\title{
Ascites is not necessarily an ominous sign in women with a pelvic tumour
}

\author{
Salah Ismail Abdelrahman, $\mathrm{MD}^{1}$. Elfadil Moh Elnagar $\mathrm{MGO}^{2}$
}

Ovarian cancer may progress from early to advanced stages within relatively a short period. Early symptoms are often vague and may resemble those of less serious conditions, such as menstrual disorders and intestinal illnesses. Ovarian cancer is called the silent killer because it progresses almost silently. By the time symptoms appear, the ovarian tumour may have grown large enough to shed cancer cells throughout the abdomen and metastasize in the chest. Ultrasound, CT- scan, MRI, and tumour markers usually suggest presence of a pelvic tumour but do not indicate reliably whether it is benign or malignant ${ }^{1,2,3}$.

The association of a benign ovarian tumour with ascites and hydrothorax that resolve after tumour resection is known as Meigs' syndrome. It usually occurs in elderly females. It was first emphasized by Meigs and Cass in $1937^{4,5}$. The importance of Meigs' syndrome is that the presence of ascites and pleural effusion does not necessarily indicate that a pelvic mass is malignant. The benign tumours in Meigs' syndrome are usually fibromas or fibrothecomas which constitute $4 \%$ of all ovarian neoplasms ${ }^{1,6}$. Here we describe a case of pelvic tumour in a young female.

\section{Case report}

A 28- year old single female from Gadarif Eastern Sudan, presented to Saad Abo el Ela Teaching Hospital with chest pain, dry cough and abdominal swelling for two months

On examination she was rather ill, not jaundiced, cyanosed or tachypnoic. Pulse 78/min, BP $110 / 65 \mathrm{mmHg}$, RR 16/min. There was diminished air entry more marked at the right side of the chest with clear stony dullness on percussion denoting presence of significant amount of pleural effusion. At examination of the abdomen a pelvi-abdominal mass, firm in consistency, rounded in shape, freely mobile with irregular surface was palpated. Vaginal examination was not possible because she was virgin.

Investigations; $\mathrm{Hb} 11 \mathrm{gm} / \mathrm{dl}$, urinalysis was clear. ESR 45mm first hour.

Chest x-ray (Fig 1) confirmed the presence of pleural effusion more marked on the right side, no evidence of parenchymal lung disease or metastases.

Ultrasonic scan showed a huge mass in pelvic cavity $16.2 \mathrm{X} 10.2 \mathrm{~cm}$ in diameter, the uterus was normal in size and shape but there was free fluid in the peritoneal cavity and free fluid in right pleural cavity.

Preliminary diagnosis of Meigs' Syndrome was made and the patient was prepared for laparotomy.

1- Obstetrician, Assis Prof Faculty of Medicine, Omdurman Islamic University.

2- Obstetrician, Assis Prof Faculty of Medicine, El Zaeem El Azhari University.
Fig 1: Bilateral pleural effusion more marked in the right side

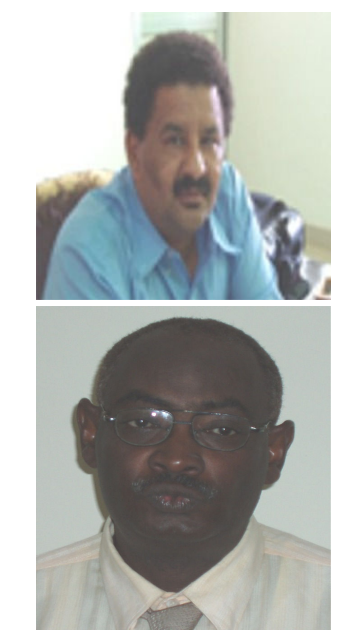

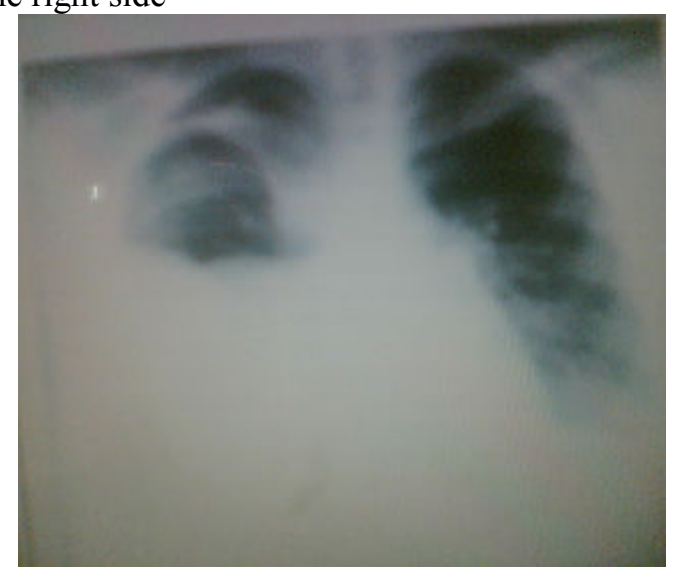

During surgery a solid irregular right ovarian mass was found, with large amount of free fluid in the peritoneal cavity, but no evidence of infiltration of the adjacent organs, liver or peritoneal metastasis. Sample of the ascetic fluid was taken for cytology and the rest of the fluid was sucked out. The mass was resected and sent for histopathology (Fig 2).

Cytology of the ascitic fluid revealed no abnormality

Histopathology made a diagnosis of fibroma of the ovary. 
Fig 2: Right overian mass more than triple the hand fist in size.

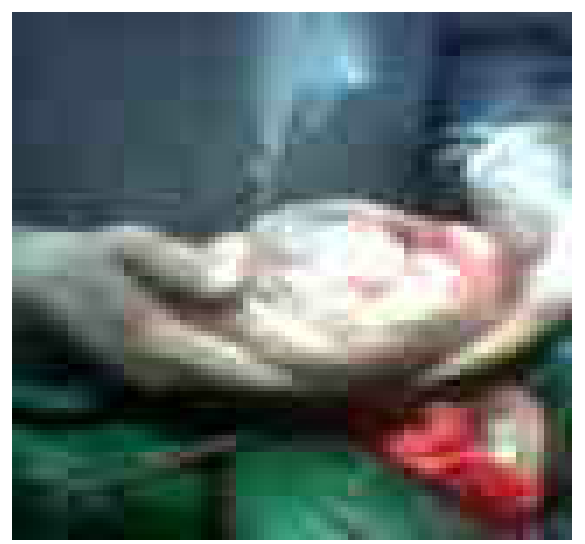

The postoperative period was uneventful. The patient was discharged home and followed in the out patient department. The pleural effusion and ascites subsided and disappeared in four weeks time (Fig 3).

Fig 3: Chest X-ray at outpatient follow up

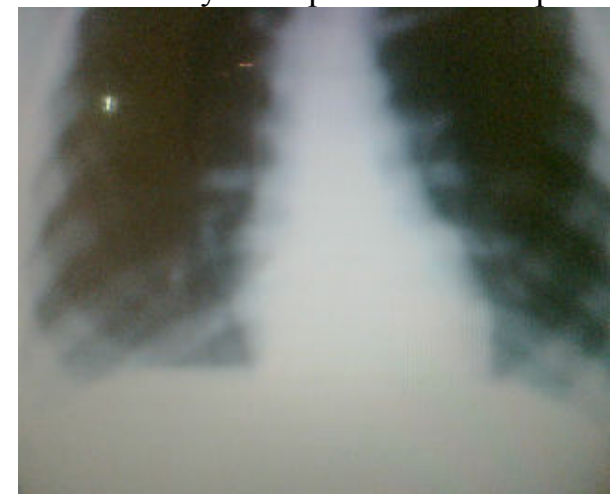

\section{Discussion:}

Meigs' syndrome is characterized by solid ovarian tumour, usually fibroma, associated with ascites and hydrothorax ${ }^{4}$. It occurs mainly in elderly women ${ }^{4,7}$. PseudoMeigs' syndrome (a term given by Meigs) is the same as true Meigs' syndrome, except that in the pseudo-Meigs' syndrome the tumour may be in the ovary, tubes, uterus or round ligament. The first report of this condition involved Dame Mary Page, wife of Sir Gregory Page, Bunhill Fields, England, who died in 1728 , in her $56^{\text {th }}$ year. Otto Spiegelberg (1830-1881) in 1866 described a patient with fibroma, ascites, and hydrothorax, and erroneously concluded that the diagnosis was "ovarian pregnancy." In 1879 Charles James Cillingworth (1841-1908) in 1887, Albert Jean Octave Demons (1842-1920) of France in 1892,
Robert Lawson Tait (1845-1899) of England followed by P. Pascale and Louis Félix Terrier (1837-1908) in 1888 described some forms of Meigs' syndrome. Meigs ${ }^{4}$ described the condition in 1934, and with John W. Cass ${ }^{5}$ in 1937 described it as a syndrome comprising ovarian fibroma, ascites and hydrothorax. Their first report disclosed details of seven cases collected during the years 1901-1934, as well as discussion of the syndrome. In the same year 1937, J. E. Rhoads and A. W. Terrell ${ }^{8}$ described another case, and these authors termed the condition Meigs' syndrome. Meigs' syndrome is also known as: Demons-Meigs' syndrome, Meigs-Cass syndrome.

Ascites in Meigs` syndrome may be due to local irritation by solid pelvic mass, or secretion of vaso-active mediators by the tumour? However, the fluid may pass through the diaphragmatic defects or lymphatic channels to form pleural effusion ${ }^{10}$.

Many ladies complain of abdominal pain and swelling months before they are diagnosed with ovarian neoplasm. Ovarian cancers are potentially life-threatening malignancies that develop in one or both ovaries. Malignant ovarian tumours generally fall into three primary classes: Epithelial tumours (90\%), germ cell and stromal tumours

Meigs' syndrome typically occurs in elderly females. However, rare cases of Meigs' and PseudoMeigs' syndrome were reported in few young females ${ }^{11,12}$ and unmarried females like our patient ${ }^{11}$.

Although clinically Meigs' syndrome looks typical to ovarian cancer, inherited genetic factors as BRCA1 and 2 or other genetic mutations that play a role in ovarian cancer do not have any impact on pelvic tumours of Meigs' syndrome. Also, the genetic alterations that have been observed in ovarian cancers as p53 tumour suppressor gene, HER2/neu gene, and PIC3KA gene and the ethnic factors were not reported to have any roll in the aetiology of tumours in Meigs' syndrome. On the other hand, women who have never had children are more likely to develop ovarian cancer than women who have reduced ovulations because of repeated pregnancies, lactations or use of birth control pills that contain the female hormones estrogen and progestin. This latest fact seems to be consistent with our patient and some other cases of reported as Meigs' syndrome ${ }^{11}$.

These comparisons are important because of the clinical similarities between malignant and benign 
ovarian tumours. In addition, CA-125 which is a protein secreted by ovarian cancer cells is elevated in over $80 \%$ of patients with ovarian cancer is found to be highly elevated in the majority of the benign Meigs' tumours2, 12, 14, 15 . Though the CA-125 blood test is not approved for screening in the general population in both conditions, oncologists usually obtain a blood test for this protein if ovarian cancer is strongly suspected but if it turn to be high it does not confirm the presence of malignancy because it is usually high in benign tumours of Meigs' syndrome. So, it is not a reliable preoperative test for diagnosis.

Therefore, any female complaining of vague abdominal pain and/or feeling of abdominal swelling (usually caused by fluid or mass within the abdomen), pelvic pressure or cramps, digestive problems such as gas, bloating, bowel and bladder problems such as constipation and frequent urination, loss of appetite or feeling of fullness even after a very light meal, unusual vaginal bleeding, back pain or leg pain should be thoroughly examined and investigated. However, neither ultrasound examination nor computed tomography or MRI can reliably offer a preoperative diagnosis. All do not provide enough specific information to reliably determine which abnormal masses are cancerous or noncancerous. It is also important to remember that a pelvic neoplasm in a woman presenting with hydrothorax, ascites, and elevated CA 125 levels might be benign and that this condition may rapidly be resolved with surgical removal ${ }^{1,2}$.

In order to establish a prognosis and determine treatment, the doctor needs to know the cell type, stage, and grade of the disease. This is why surgery should not be denied and it will not be astonishing to end with a final diagnosis of Meigs's syndrome due to fibroma ${ }^{1,7}, 15,16$ or thecoma of the ovary ${ }^{17}$ or Pseudomeigs' syndrome due to a benign pathology such as leiomyoma with focal hyaline and extensive hydropic degeneration $^{18}$, leiomyoma with parasitized blood supply from the omentum ${ }^{19}$, leiomyoma of the ovary $^{20}$, utrine leiomyoma ${ }^{21,22,23,24}$, benign Brenner tumours $^{25}$ ovarian hemangioma ${ }^{26}$, granulosa cell tumour $^{27}$, dysgerminoma ${ }^{28}$, struma ovarii a specialized ovarian teratoma composed predominantly of mature thyroid tissue ${ }^{29,30,31}$, benign mature teratoma ${ }^{11}$, or malignant disease as malignant struma ovarii ${ }^{32}$ and secondaries from carcinoma of stomach (Krukenberg tumors ) ${ }^{33}$, colon $^{34}$ or epithelial cell ovarian cancer $^{35}$, and malignant mixed germ cell tumour of the ovary ${ }^{36}$

\section{References}

1. Nemeth AJ, Patel SK. Meigs syndrome revisited. J Thorac Imaging. 2003;18(2):100-3.

2. Timmerman D, Moerman P, Vergote I. Meigs' syndrome with elevated serum CA 125 levels: two case reports and review of the literature. Gynecol Oncol. 1995;59(3):405-8

${ }^{3}$. Choi K, Lee HJ, Pae JC, et al. Ovarian granulosa cell tumor presenting as Meigs' syndrome with elevated CA125. Korean J Intern Med. 2005;20(1):105-9.

${ }^{4}$. J. V. Meigs: Tumors of the female pelvic organs. New York, Macmillan, 1934: 262-263.

5 . J. V. Meigs; J. W. Cass: Fibroma of the ovary with ascites and hydrothorax, with a report of seven cases. American Journal of Obstetrics and Gynecology, St. Louis, 1937; 33: 249-267.

6. Sutton CL, McKinney CD, Jones JE et al. Ovarian masses revisited: Radiologic and pathologic correlation. Radiographics 1992;12:853-77

7. Siddiqui M, Toub DB. Cellular fibroma of the ovary with Meigs' syndrome and elevated CA-125. A case report. J Reprod Med. 1995; 40(11):817-9.

${ }^{8}$. Rhoads JE, Terrell AW. Ovarian fibroma with ascites and hydrothorax (Meigs' syndrome). The Journal of the American Medical Association, Chicago, 109: 16841687

9. Abramov Y, Anteby SO, Fasouliotis SJ et al. Markedly elevated levels of vascular endothelial growth factor, fibroblast growth factor, and interleukin 6 in Meigs syndrome. Am J Obstet Gynecol. 2001 Feb;184(3):354-5

10. Santopaolo O, Rotondo A, Alfe M et al. Meigs syndrome with bilateral hydrothorax. Minerva Ginecol. 1993 May;45(5):263-6

11. Kazanov L, Ander DS, Enriquez E et al. PseudoMeigs' Syndrome. Am J Emerg Med. 1998; 16(4):4045.

12. Weise M, Westphalen S, Fayyazi A et al. Pseudomeigs syndrome: uterine leiomyoma with bladder attachment associated with ascites and hydrothorax - a rare case of a rare syndrome. Onkologie. 2002; 25(5):443-6.

13. Baloch S, Khaskheli M, Khushk IA et al. Meigs' syndrome. J Coll Physicians Surg Pak. 2006; 16(9):602-3.

14. Shiau CS, Chang MY, Hsieh CC et al. Meigs' syndrome in a young woman with a normal serum CA125 level. Chang Gung Med J. 2005; 28(8):587-91.

15. Moran-Mendoza A, Alvarado-Luna G, CalderilloRuiz G et al. Elevated CA125 level associated with Meigs' syndrome: case report and review of the literature. Int J Gynecol Cancer. 2006;16 Suppl 1:3158

${ }^{16}$. Latta RJ, Lee PD. Meigs' syndrome in a young woman. J Adolesc Health Care. 1981; 1(4):313-5.

${ }^{17}$. Renaud MC, Plante M, Roy M. Ovarian thecoma associated with a large quantity of ascites and elevated serum CA 125 and CA 15-3. J Obstet Gynaecol Can. 2002; 24(12): 963-5. 
18. Dunn JS Jr, Anderson CD, Method MW et al. Hydropic degenerating leiomyoma presenting as pseudo-Meigs syndrome with elevated CA 125 . Obstet Gynecol. 1998; 92(4 Pt 2):648-9.

19. Kebapci M, Aslan O, Kaya T et al. Pedunculated uterine leiomyoma associated with pseudo-Meigs' syndrome and elevated CA-125 level: CT features. Eur Radiol. 2002; 12 Suppl 3:S127-9. Epub 2002 May 22.

${ }^{20}$. Kurai M, Shiozawa T, Noguchi H et al. Leiomyoma of the ovary presenting with Meigs' syndrome. J Obstet Gynaecol Res. 2005; 31(3):257-62.

21. Terada S, Suzuki N, Uchide K et al. Uterine leiomyoma associated with ascites and hydrothorax. Gynecol Obstet Invest. 1992;33(1):54-8

${ }^{22}$. Amant F, Gabriel C, Timmerman D et al. PseudoMeigs' syndrome caused by a hydropic degenerating uterine leiomyoma with elevated CA 125. Gynecol Oncol. 2001; 83(1):153-7

23. Weise M, Westphalen S, Fayyazi A et al. Pseudomeigs syndrome: uterine leiomyoma with bladder attachment associated with ascites and hydrothorax - a rare case of a rare syndrome. Onkologie. 2002; 25(5):443-6.

24. Cuillier F, David K, Tanguy M. An atypical Demons-Meigs syndrome. Gynecol Obstet Fertil. 2002; 30(5): 390-3.

25. Meigs' syndrome with an elevated CA 125 from benign Brenner tumors. Obstet Gynecol. 2001; 98(5 Pt 2):980-2

26. Kaneta Y, Nishino R, Asaoka K et al. Ovarian hemangioma presenting as pseudo-Meigs' syndrome with elevated CA125. J Obstet Gynaecol Res. 2003;29(3): 132-5.

${ }^{27}$. Choi K, Lee HJ, Pae JC et al. Ovarian granulosa cell tumor presenting as Meigs' syndrome with elevated CA125. Korean J Intern Med. 2005; 20(1):105-9.
28. Gucer F, Oz-Puyan F, Mulayim N et al. Ovarian dysgerminoma associated with Pseudo-Meigs' syndrome and functioning ovarian stroma: a case reportGynecol Oncol. 2005; 97(2):681-4

29. Huh JJ, Montz FJ, Bristow RE. Struma ovarii associated with pseudo-Meigs' syndrome and elevated serum CA 125. Gynecol Oncol. 2002; 86(2):231-4

30. Bethune M, Quinn M, Rome R. Struma ovarii presenting as acute pseudo-Meigs syndrome with an elevated CA 125 level. Aust N Z J Obstet Gynaecol. 1996; 36(3): 372-3.

${ }^{31}$. Loizzi V, Cormio G, Resta L et al. Pseudo-Meigs syndrome and elevated CA125 associated with struma ovarii. Gynecol Oncol. 2005; 97(1):282-4.

32. Zannoni GF, Gallotta V, Legge F et al. PseudoMeigs' syndrome associated with malignant struma ovarii: a case report. Gynecol Oncol. 2004; 94(1):2268.

${ }^{33}$. Cetin B, Aslan S, Akinci M et al. A long surviving case of Pseudomeigs' syndrome caused by Krukenberg tumor of the stomach. Jpn J Clin Oncol. 2005; $35(4): 221-3$

34. Feldman ED, Hughes MS, Stratton P,Gynecol Oncol. Pseudo-Meigs' syndrome secondary to isolated colorectal metastasis to ovary: a case report and review of the literature 2004; 93(1):248-51.

${ }^{35}$. Shimizudani N, Senba S, Komiyama M et al. A case of pseudo-meigs syndrome due to ovarian clear cell adenocarcinoma. Nihon Kokyuki Gakkai Zasshi. 2005; 43(4):236-40

36. Wolff AL, Ladd AP, Kumar M et al. Pseudo-Meigs syndrome secondary to ovarian germ cell tumor. J Pediatr Surg. 2005; 40(4):737-9. 